\title{
An Audit of the Physiotherapy Services AT THE JOHANNESBURG HOSPITAL
}

\author{
ACKNOWLEDGEMENT: The authors would like to thank all the physiotherapists at the Johannesburg Hospital \\ and the University of the Witwatersrand for their help with this audit.
}

\begin{abstract}
In 1998 the Gauteng Department of Health notified the Physiotherapy Department of the Johannesburg hospital that the number of physiotherapy posts would be cut from 43 full-time posts to 22 full-time posts. This cut in workforce made it essential to re-evaluate the services rendered in order to meet the needs of the hospital. An audit of the number of inpatients on a given day was

\section{DE CHARMOY S, MSc (Physio) EALES CJ, PhD ${ }^{2}$} IPhysiotheropy Department, University of the Witwatersrand
${ }^{2}$ Physiotherapy Department, University of the Witwatersrand conducted in June 1998. In addition to this the number of patients requiring physiotherapy and the time needed to treat them was determined. A second study established the time spent by physiotherapists in direct patient care, indirect patient care and "social" activities. From the results of this audit it was established that 22 full-time physiotherapists would not be able to provide a comprehensive physiotherapy service. Since the completion of this audit the number of physiotherapists at the Johannesburg hospital has decreased further with no re-appointments due to cuts in the Gauteng health budget. It is the opinion of the authors that many hospitals in South Africa are in similar positions and that more studies need to be done at hospitals to determine the need for physiotherapy in other hospitals.
\end{abstract}

\section{KEYWORDS: AUDIT, GAUTENG HEALTH DEPARTMENT, PHYSIOTHERAPY SERVICES}

$I^{2}$ 1998 the Gauteng Department of Health notified the physiotherapy department at Johannesburg hospital that their total number of physiotherapy posts would be cut from 43 full-time posts to 22 full-time posts. This drastic cut in workforce made it essential to re-evaluate the services rendered in order to meet the needs of patients. A new and different way of delivering physiotherapy services would need to be established. Some services would have to be downscaled or omitted completely. In order to establish the physiotherapy needs of the Johannesburg hospital, an audit was done of the existing service. The first step was to determine the physiotherapy needs of patients in the hospital on a given day.

\section{METHOD:}

On Wednesday 24 June 1998 an audit of the physiotherapy services at the Johannesburg hospital was conducted. The total number of patients in each unit was determined and all patients requiring physiotherapy were identified. The time required for physiotherapy for each patient was established in terms of treatment units. Patients in each area (such as neurology, paediatrics, and orthopaedics) were assessed by a senior physiotherapist working in the area and a member of the university staff who teaches and supervises students within that clinical area.

The following key areas were identified: - paediatrics;

- surgical wards, including trauma, plastic surgery, cardiothoracic surgery and the general surgical wards;

- medical wards, including oncology;

- intensive care units;

- orthopaedics; out-patients were excluded;

- neurology; out-patients were excluded;

- exercise rehabilitation; one out-patient clinic included.

The outpatient department (OPD) was not included, as this was the first area from which the physiotherapy services were withdrawn when the staff numbers were cut. The reasons being that the hospital is an acute care facility and at that stage there were alternative hospitals in the near vicinity of the Johannesburg hospital that could supply an out-patient service.

The following parameters were used on the information sheet:
1. The number of patients within a specific ward.

2. Diagnoses of patients.

3. Whether or not physiotherapy was indicated.

4. If the patient required physiotherapy then the choice of physiotherapy could be documented in the following way: respiratory, musculoskeletal, ambulating/exercise, neurological rehabilitation or simply "check". A check was considered attention paid to a patient who would not benefit from physiotherapy at that particular time but who would be continually assessed to determine the need for physiotherapy should it arise (for instance patients in the immediate post-operative period).

\section{CORRESPONDENCE:}

Sue de Charmoy Physiotherapy Department University of the Witwatersrand

7 York Road Parktown 2193

Tel: (01 1) 488-3450 (w) (011) 678-8592 (h)

Fax: (011) 488-3210

Email: 159suz@chiron.wits.ac.za 
TABLE 1: A comparison between patient and unit counts of hospital staff and lecturing staff

\begin{tabular}{|c|c|c|c|c|c|c|c|c|}
\hline \multicolumn{6}{|c|}{$\begin{array}{l}\text { Lecturing } \\
\text { Staff }\end{array}$} & \multicolumn{3}{|c|}{$\begin{array}{c}\text { Hospital } \\
\text { Staff }\end{array}$} \\
\hline & $\begin{array}{c}\text { Total } \\
\text { Patients }\end{array}$ & $\begin{array}{c}\text { PT } \\
\text { Patients }\end{array}$ & Units & Contacts & $\begin{array}{c}\text { Total } \\
\text { Patients }\end{array}$ & $\begin{array}{c}\text { PT } \\
\text { Patients }\end{array}$ & Units & Contacts \\
\hline Paediatrics & 119 & 49 & 72 & 49 & 139 & 27 & 45 & 35 \\
\hline Surgical & 187 & 51 & 73 & 53 & 112 & 66 & 96 & 76 \\
\hline Medical & 200 & 98 & 67 & 60 & 198 & 118 & 267 & 139 \\
\hline $\mathrm{ICU}$ & 34 & 26 & 63 & 40 & 33 & 21 & 47 & 28 \\
\hline Orthopaedics & 64 & 57 & 80 & 58 & 64 & 60 & 96 & 61 \\
\hline Neurology & 102 & 68 & 146 & 75 & 103 & 65 & 139 & 91 \\
\hline Ex Rehab & 80 & 78 & 27 & 14 & 79 & 75 & 22 & 13 \\
\hline Total & 786 & 425 & 528 & 349 & 728 & 432 & 712 & 443 \\
\hline
\end{tabular}

PT: Physiotherapy

5. The number of treatment units was then established - a unit was considered a treatment session lasting up to 15 minutes, thus if "2" was recorded it indicated that a half-hour of treatment was considered necessary.

6. Finally, staff members also recorded the number of physiotherapy treatments (contacts) the patient should have in a day. That is if the number of units read 4 and the number of contacts was 2 then the patient would require two half-hour treatment sessions totalling one hour.

The two assessors assessed the patients independently so that there could be no collusion when determining physiotherapy needs. All units recorded were simply direct patient care i.e. "hands on" treatment.

The hospital physiotherapists' estimates were totalled for each area as were those of the lecturing staff. The results of the two groups were then compared (see Table 1).

The information obtained was then used to determine the number of physiotherapists required to provide the necessary service. Assuming that physiotherapists worked eight hours a day "hands on" and disregarding all other forms of patient interaction, then one could deduce that it would be possible to cover 32 units per day ( $8 \mathrm{hrs} \mathrm{x} 4$ units per hour). To calculate the physiotherapy needs, the total number of treatment units for the hospital was divided by 32 to work out the number of physiotherapy "hands on" hours required to provide the service.

Such an eight-hour day did not take into consideration administrative duties or interactions with other team members. It was proposed that a more realistic figure of direct patient care be determined. The second part of this study involved establishing how much direct patient care the physiotherapists at the Johannesburg hospital were doing in a day. In order to do this the physiotherapists were categorised as executive staff (the physiotherapists running the hospital service), chiefs, senior physiotherapists and junior physiotherapists. Physiotherapists were randomly selected from each of these categories and assigned an assessor who was either a member of the hospital staff or a lecturer.

The assessor randomly selected a day to follow the physiotherapist. The assessor stayed with the physiotherapist throughoul the day and documented the time spent in minutes on the following categories:
1. Direct patient care, which involved direct hands on treatment for the patient.

2. Indirect patient care, which involved ordering appliances, telephone conversations related to the patient, attending ward rounds, student supervision etc.

3. Social - this involved tea, lunch, social telephone conversations i.e. anything not related directly to patient care.

4. The data was then collated and the minutes of the day spent on each activity calculated. The three activities could then be presented as a percentage of the total time at work. (Table 2).

\section{RESULTS AND DISCUSSION:}

There was a discrepancy in the total number of patients in the paediatric and surgical wards as counted by the two independent assessors. In the paediatric unit the hospital staff member assessed an extra two wards that the lecturer did not assess. In the surgical unit the difference in total number of patients (75) was due to the hospital staff member not assessing three of the wards due to time constraints. The differences in number of patients for physiotherapy, units and number of contacts are largely accounted for by the discrepancy in the medical and surgical wards. 
TABLE 2: Percentage time spent during a working day

\begin{tabular}{|l|c|c|c|}
\hline & Direct & Indirect & Social \\
\hline Executive $(\mathrm{F} / \mathrm{T})$ & $50 \%$ & $22 \%$ & $28 \%$ \\
\hline Chief $(\mathrm{F} / \mathrm{T})$ & $50 \%$ & $42 \%$ & $8 \%$ \\
\hline Senior (F/T) & $55 \%$ & $37 \%$ & $8 \%$ \\
\hline Senior (P/T) & $23 \%$ & $68 \%$ & $9 \%$ \\
\hline Junior (P/T) & $44 \%$ & $44 \%$ & $12 \%$ \\
\hline Junior (F/T) & $43 \%$ & $43 \%$ & $12 \%$ \\
\hline Limited registration (P/T) & $47 \%$ & $41 \%$ & $12 \%$ \\
\hline Mean & $45 \%$ & $42 \%$ & $13 \%$ \\
\hline
\end{tabular}

F/T: Full-time

$\mathrm{P} / \mathrm{T}$ : Part-time

When comparing the results of the lecturing staff with the hospital staff there was good correlation (the perfect correlation being 1.00) between the total number of patients in the hospital (0.87); the number of physiotherapy patients (0.93); and the number of contacts (0.74). However there was a poor correlation for the number of treatment units $(0.34)$. This poor correlation was attributed to the large discrepancy in the assessment of the units of treatment thought to be required in the medical and surgical wards. The discrepancy in these counts may be due to different schools of thought. An older hospital therapist assessed the medical wards and this therapist's figures may reflect the treatment scenario that was possible in previous years when there was less emphasis on outcome and more resources available. The lecturer may have had a more realistic appraisement in terms of the availability of resources. The same may be the case for the surgical wards however it is difficult to draw conclusion as not all the surgical wards were completely assessed by both assessors.

The next step of the audit investigated the time actually spent by the physiotherapists on various activities during a day. As can be seen from Table 2, physio- therapists at the Johannesburg hospital spent an average of $45 \%$ of their time treating patients, and $42 \%$ of their time in indirect patient care. In order to determine the number of physiotherapists required to treat the identified patients, we could assume that each physiotherapist could render 16 units of direct patient care a day as $50 \%$ of their time is A total of approximately 620 units $(528+712=1240 / 2)$ needs to be completed on a given day. This would mean that 39 full time physiotherapists would need to be employed to adequately meet the physiotherapy needs of the Johannesburg hospital.

The above figures merely reflect time spent with the patient versus other activities. We can draw no conclusions from them about the quality of work produced within the "time" frames. It is of concern that the physiotherapists are spending an equal amount of time treating the patient as they are on indirect patient care. One of the reasons cited for this by the therapists is the decrease in the number of nurses. This has resulted in more demands on physiotherapists time doing what the nursing staff had previously done. Furthermore it does not fit in with the actual job description of each category that all levels of physiotherapists spent on direct "hands on" patient care. are doing the same amount of direct patient care.

As the prospect of 39 posts at the Johannesburg Hospital is unlikely it would seem on the current post structure that each physiotherapist would have to be involved with direct patient care $88 \%$ of the time which translates to seven hours a day. This is an additional three hours of direct patient care per day per physiotherapist in addition to what they were doing at the time of this study. State employees have to work $81 / 2$ hours in a day to allow for lunch and tea but it does mean that no time would be available for indirect patient care. In order to give an adequate physiotherapy service it is essential that a certain portion of the day is allocated to consultation with team members re the requirements of the patient, ward rounds and further development of the physiotherapist as a professional. Such a situation would therefor be unacceptable.

It would thus seem that the staff situation in 1998 was not sufficient to meet the needs of the physiotherapy service required at the time of this audit and further steps have to be taken in order to make the current service more efficient to meet the demands for physiotherapy. The next step of this audit will be to look at essential services, time management of staff and effective levels of communication, in an attempt to change the current situation into a realistic and viable physiotherapy service.

Since the completion of this audit the number of physiotherapists at the Johannesburg hospital has decreased even further with no re-appointments due to financial constraints in the Gauteng health budget. The Johannesburg hospital is used in this audit as an example. It is the opinion of the authors that all the hospitals in South Africa are in a similar position and that further studies need to be done at other centres to determine the need for physiotherapy in specific areas.

Based on the outcome of this survey a completely new look at the structuring of physiotherapy services in state departments is required in order to try and provide a reasonable, efficient and practical service. 